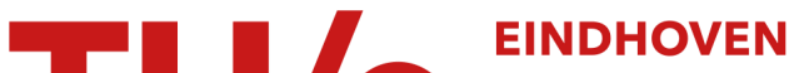 \\ UNIVERSITY OF \\ TECHNOLOGY
}

\section{Characterization of ultraviolet-cured methacrylate networks}

Citation for published version (APA):

Anastasio, R., Peerbooms, W., Cardinaels, R., \& van Breemen, L. C. A. (2019). Characterization of ultravioletcured methacrylate networks: from photopolymerization to ultimate mechanical properties. Macromolecules, 52(23), 9220-9231. https://doi.org/10.1021/acs.macromol.9b01439

\section{Document license:}

CC BY-NC-ND

DOI:

10.1021/acs.macromol.9b01439

Document status and date:

Published: 10/12/2019

\section{Document Version:}

Publisher's PDF, also known as Version of Record (includes final page, issue and volume numbers)

\section{Please check the document version of this publication:}

- A submitted manuscript is the version of the article upon submission and before peer-review. There can be important differences between the submitted version and the official published version of record. People interested in the research are advised to contact the author for the final version of the publication, or visit the $\mathrm{DOI}$ to the publisher's website.

- The final author version and the galley proof are versions of the publication after peer review.

- The final published version features the final layout of the paper including the volume, issue and page numbers.

Link to publication

\section{General rights}

Copyright and moral rights for the publications made accessible in the public portal are retained by the authors and/or other copyright owners and it is a condition of accessing publications that users recognise and abide by the legal requirements associated with these rights.

- Users may download and print one copy of any publication from the public portal for the purpose of private study or research.

- You may not further distribute the material or use it for any profit-making activity or commercial gain

- You may freely distribute the URL identifying the publication in the public portal.

If the publication is distributed under the terms of Article $25 \mathrm{fa}$ of the Dutch Copyright Act, indicated by the "Taverne" license above, please follow below link for the End User Agreement:

www.tue.nl/taverne

Take down policy

If you believe that this document breaches copyright please contact us at:

openaccess@tue.nl

providing details and we will investigate your claim. 


\title{
Characterization of Ultraviolet-Cured Methacrylate Networks: From Photopolymerization to Ultimate Mechanical Properties
}

\author{
R. Anastasio, ${ }^{\dagger, \ddagger, \S}$ W. Peerbooms, ${ }^{\dagger, \S}$ R. Cardinaels, ${ }^{\dagger}$ and L. C. A. van Breemen ${ }^{*} \dagger$ (®) \\ ${ }^{\dagger}$ Department of Mechanical Engineering, Polymer Technology, Materials Technology Institute, Eindhoven University of \\ Technology, P.O. Box 513, 5600 MB Eindhoven, The Netherlands \\ ${ }^{\ddagger}$ Brightlands Materials Center (BMC), P.O. Box 18, 6160 MD Geleen, The Netherlands
}

Supporting Information

\begin{abstract}
In this study, the effect of different process conditions on the material properties of a single UV-cured layer of methacrylate resin, typically used in the stereolithography (SLA) process, is assessed. This simplified approach of the SLA process gives the opportunity to study the link between process conditions and mechanical properties without complicated interactions between different layers. Fourier-transform infrared analysis is performed to study the effect of light intensity, curing time, and initiator concentration on the monomer conversion. A model is developed based on the reaction kinetics of photopolymerization that describes and predicts the experimental data. The effect of curing time and light intensity on the glass-transition temperature is studied. A unique relation exists between conversion and glass-transition temperature, independent of the light intensity and curing time. Tensile tests on UV-cured resin show an increase in yield stress with increasing curing time and

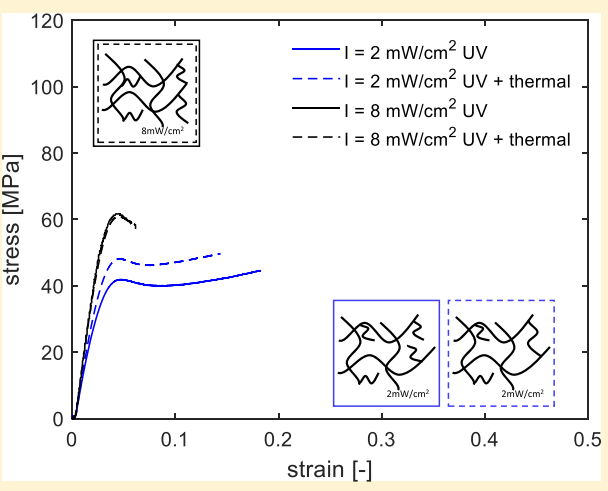
a linear relation between glass-transition temperature and yield stress. However, a lower light intensity leads to a different network structure characterized by a lower yield stress and glass-transition temperature. The correlations between process conditions and the mechanical properties of UV-cured methacrylate systems are established to better understand the role of the processing parameters involved in the SLA process.
\end{abstract}

\section{INTRODUCTION}

In recent years, the interest in additive manufacturing (AM) has increased enormously. The possibility to produce complex geometries without the need for postprocessing gives tremendous design freedom. This freedom makes AM suitable for numerous applications. One of the most important AM methods is stereolithography (SLA), which was already developed during the 1970 s. ${ }^{1}$ SLA is a $3 \mathrm{D}$ printing method that uses ultraviolet (UV) light to solidify specific parts of a layer of photocurable polymers. The SLA technique results in products with a high spatial resolution and low porosity. Despite these advantages, high shrinkage and poor mechanical properties of the printed products limit the use of SLA for load-bearing applications. Optimization of product quality is often done based on trial and error because of the lack of understanding of the effect of process conditions on the mechanical properties. Research has been done to study the material properties of products produced using SLA and efforts have been made to improve the quality. ${ }^{2-7}$ These studies mainly focused on the curing characteristics, the effect of uncured monomer trapped in the network, and the shrinkage of cured products. Additionally, the photopolymerization process has been modeled to improve the understanding of the reaction kinetics. ${ }^{8-10}$ Nevertheless, improvements can be made by developing better understanding of the polymerization process and studying the effect of process conditions on the curing mechanism of the resin and its relation to mechanical properties. Capturing these relations in a model creates the possibility to incorporate the influence of processing to obtain ultimate mechanical properties, without the need for trial and error type of experiments.

In the printing process, several parameters influence the polymerization reactions and resulting mechanical properties, such as light intensity, irradiation time, and initiator concentration. Lovell et al. ${ }^{11}$ have studied the effect of light intensity on the rate of photopolymerization, reporting an increase in polymerization rate, and therefore ultimate conversion, with increasing intensity. Moreover, Nomoto et al. ${ }^{12}$ have shown that when the total dose is kept constant, the curing depth and evolution of monomer conversion are the same. Miyazaki at al. ${ }^{13}$ have found equivalent fracture toughness, flexural strength, and modulus values for lightcured materials when equivalent doses were applied. Others have reported a linear relationship between monomer conversion and glass-transition temperature for dimethacrylate systems. $^{2,14}$

In this work, polymerization kinetics and mechanical properties of a methacrylate resin UV-cured under different

Received: July 10, 2019

Revised: October 24, 2019

Published: November 25, 2019 
process conditions are studied. Single layers of methacrylate resin are characterized to study how process conditions of resins used in the SLA process affect the mechanical properties, without complicated interactions between different layers. The effect of light intensity, curing time, and initiator concentration on the monomer conversion is studied. A model based on the reaction kinetics is developed to describe the monomer conversion. The effects of curing time and light intensity on the glass-transition temperature and mechanical properties are presented as well as relations between conversion and ultimate properties.

\section{MODELING OF MATERIAL PROPERTIES}

The models used in this study describe the material properties of the methacrylate resin including monomer conversion, that is, kinetics of photopolymerization, as well as link the monomer conversion to the glass-transition temperature, and capture the yield kinetics.

2.1. Modeling Monomer Conversion. Modeling the monomer conversion is done by using the kinetics of the photopolymerization reaction.

2.1.1. Reaction Scheme of Photopolymerization. The photopolymerization follows the reaction scheme shown in 1. ${ }^{18,20}$ The first step is the decomposition of an initiator molecule (In), creating two free radicals $\left(\mathrm{R}^{\bullet}\right)$. The rate constant of this decomposition is defined as $k_{\mathrm{d}}$.

$$
\text { In } \stackrel{k_{\mathrm{d}}}{\rightarrow} 2 \mathrm{R}^{\bullet}
$$

The initiation of a polymer chain $\left(\mathrm{P}^{\bullet}\right)$ happens when a free radical reacts with a monomer $(\mathrm{M})$. This polymer chain propagates by reacting with monomer molecules. The rate of these two reactions is assumed equal and is represented by $k_{\mathrm{p}}$, that is, the propagation rate constant.

$$
\begin{aligned}
& \mathrm{R}^{\bullet}+\mathrm{M} \stackrel{k_{\mathrm{p}}}{\rightarrow} \mathrm{P}^{\bullet} \\
& \mathrm{P}^{\bullet}+\mathrm{M} \stackrel{k_{\mathrm{p}}}{\rightarrow} \mathrm{P}^{\bullet}
\end{aligned}
$$

Termination of the polymer chains occurs through either the reaction of a polymer chain with a free radical, combination, or disproportionation. For simplicity of the developed model, combination and disproportionation are modeled in one equation. This is allowed because the kinetics of cross-linked systems are not affected significantly by the termination mechanism, in contrast to linear systems for which the molecular weight is affected. ${ }^{15}$ The rate of these termination processes is assumed equal and is represented by $k_{\mathrm{t}}$, that is, the termination rate constant.

$$
\begin{aligned}
& \mathrm{P}^{\bullet}+\mathrm{P}^{\bullet} \stackrel{k_{\mathrm{t}}}{\rightarrow} \mathrm{P}_{\text {dead }} \\
& \mathrm{P}^{\bullet}+\mathrm{R}^{\bullet} \stackrel{k_{\mathrm{t}}}{\rightarrow} \mathrm{P}_{\text {dead }}
\end{aligned}
$$

The evolution of species concentrations over time is derived from the reaction scheme, obtaining the set of differential equations shown in 6 to 10 . In this set of equations, [In], [ $\left.\mathrm{R}^{\bullet}\right]$, $[\mathrm{M}],\left[\mathrm{P}^{\bullet}\right]$, and $\left[\mathrm{P}_{\text {dead }}\right]$ are the concentrations of initiator, free radicals, monomer, growing polymer chains, and dead polymer chains, respectively.

$$
\frac{\mathrm{d}[\operatorname{In}]}{\mathrm{d} t}=-k_{\mathrm{d}}[\operatorname{In}]
$$

$$
\begin{aligned}
& \frac{\mathrm{d}\left[\mathrm{R}^{\bullet}\right]}{\mathrm{d} t}=2 f k_{\mathrm{d}}[\mathrm{In}]-k_{\mathrm{p}}[\mathrm{M}]\left[\mathrm{R}^{\bullet}\right]-k_{\mathrm{t}}\left[\mathrm{P}^{\bullet}\right]\left[\mathrm{R}^{\bullet}\right] \\
& \frac{\mathrm{d}[\mathrm{M}]}{\mathrm{d} t}=-k_{\mathrm{p}}[\mathrm{M}]\left[\mathrm{R}^{\bullet}\right]-k_{\mathrm{p}}[\mathrm{M}]\left[\mathrm{P}^{\bullet}\right] \\
& \frac{\mathrm{d}\left[\mathrm{P}^{\bullet}\right]}{\mathrm{d} t}=k_{\mathrm{p}}[\mathrm{M}]\left[\mathrm{R}^{\bullet}\right]-k_{\mathrm{t}}\left[\mathrm{P}^{\bullet}\right]\left[\mathrm{R}^{\bullet}\right]-2 k_{\mathrm{t}}\left[\mathrm{P}^{\bullet}\right]^{2} \\
& \frac{\mathrm{d}\left[\mathrm{P}_{\text {dead }}\right]}{\mathrm{d} t}=k_{\mathrm{t}}\left[\mathrm{P}^{\bullet}\right]^{2}+k_{\mathrm{t}}\left[\mathrm{P}^{\bullet}\right]\left[\mathrm{R}^{\bullet}\right]
\end{aligned}
$$

in which $f$ is the initiator efficiency that describes the fraction of radicals initiating a polymer chain. This set of ordinary differential equations can be solved if the initial conditions, the reaction rate constants, and the initiator efficiency are known.

2.1.2. Determination of Reaction Rate Constants. In order to solve this set of differential equations, the reaction rate constants $k_{\mathrm{d}}, k_{\mathrm{p}}$, and $k_{\mathrm{t}}$ have to be determined. The initiator decomposition rate is determined using a modified BeerLambert law ${ }^{18}$ for penetration of light into a medium

$$
k_{\mathrm{d}}=2.3 \phi \varepsilon I_{0} \exp ^{(-2.3 \varepsilon[\operatorname{In}] z)}\left(\frac{\lambda}{N_{\mathrm{A}} h c}\right)
$$

with $\phi$ the quantum yield of the initiator, $\varepsilon$ the molar absorptivity of the initiator, $I_{0}$ the incident light intensity, $z$ the depth into the material, $\lambda$ the wavelength of the light, $N_{\mathrm{A}}$ Avogadro's constant, $h$ Planck's constant, and $c$ the speed of light.

The propagation and termination rate constants are determined experimentally using Fourier transform infrared (FTIR) measurements. A setup is developed to enable in situ UV-curing of the resin on which FTIR measurements are carried out. Using this setup, the conversion is measured by intermittently illuminating the resin and performing FTIR scans, giving the possibility to obtain information about the reaction kinetics of the photopolymerization. From these experiments, the ratio $k_{\mathrm{p} 0} / k_{\mathrm{t} 0}^{0.5}$ is determined ${ }^{21}$

$$
\frac{k_{\mathrm{p} 0}}{k_{\mathrm{t} 0}^{0.5}}=\frac{R_{\mathrm{p}}}{\left(\phi I_{\mathrm{A}}\right)^{0.5}[\mathrm{M}]}
$$

with $R_{\mathrm{p}}$ the initial rate of polymerization and $I_{\mathrm{A}}$ the photon absorption rate. The rate of polymerization is defined as ${ }^{21}$

$$
R_{\mathrm{p}}=\frac{\mathrm{d} x}{\mathrm{~d} t}[\mathrm{M}]_{0}
$$

in which $x$ is the monomer conversion determined by FTIR and $[\mathrm{M}]_{0}$ is the monomer concentration in the unreacted resin. The photon absorption rate is determined from the process conditions and the material properties of the photoinitiator, using 22

$$
I_{\mathrm{A}}=I_{0} \cdot \frac{\lambda}{N_{\mathrm{A}} h c} \cdot \frac{1}{z} \cdot\left(1-\exp ^{-2.3 \varepsilon[\operatorname{In}] z}\right)
$$

2.1.3. Implementing Nonconstant Reaction Rates. The reaction rate constants $k_{\mathrm{p}}$ and $k_{\mathrm{t}}$ are a function of conversion because diffusion can become the limiting factor. At the start of the reaction, the medium consists of a monomer and a small amount of initiator. During the reaction, this composition changes as the monomer is converted into a polymer, which increases the viscosity of the medium, limiting the diffusion of the components to a point where the diffusion becomes the 
limiting step in the reaction. Additionally, in cross-linking polymers the network limits the diffusion of small molecules through the medium even more and prohibits the diffusion of large polymer chains that are connected to the network.

Anseth and Bowman ${ }^{23}$ describe a model which includes the diffusion effects on the reaction rates with a limited amount of adjustable parameters. This model describes the reaction rates in good agreement with experimental results. ${ }^{24}$ The model includes reaction diffusion, transition from reaction-controlled to diffusion-controlled reaction, and volume relaxation. The model expresses the reaction rate constants in terms of the resistances to reaction

$$
\frac{1}{k}=\frac{1}{k_{\mathrm{r}}}+\frac{1}{k_{\mathrm{m}}}
$$

with $k_{\mathrm{r}}$ the true reaction rate constant and $k_{\mathrm{m}}$ the mass transfer limited reaction rate constant.

Using this approach, the propagation rate constant is described by ${ }^{23}$

$$
k_{\mathrm{p}}=k_{\mathrm{p} 0} \frac{1}{1+\exp \left[B\left(\frac{1}{v_{\mathrm{f}}}-\frac{1}{v_{\mathrm{f}, \mathrm{p}}}\right)\right]}
$$

in which $k_{\mathrm{p} 0}$ is the initial propagation rate constant, $B$ an adjustable parameter, $v_{\mathrm{f}}$ the fractional free volume of the system, and $v_{\mathrm{f}, \mathrm{cp}}$ the critical free volume at which propagation becomes diffusion-controlled. The fractional free volume of the system is described by $^{23}$

$$
v_{\mathrm{f}}=v_{\mathrm{f}, \mathrm{eq}}+\frac{v-v_{\infty}}{v_{\infty}}
$$

with $v$ the specific volume, $v_{\infty}$ the equilibrium specific volume, and $v_{\mathrm{f}, \mathrm{eq}}$ the equilibrium free volume. The volume relaxation, described in the second term of eq 17 , is neglected in the implementation of the reaction rates in the developed model; a consequence of this simplification is that eq 17 reduces to $v_{\mathrm{f}}=$ $v_{\mathrm{f}, \mathrm{eq}}$. The equilibrium free volume is defined $\mathrm{as}^{23}$

$$
v_{\mathrm{f}, \mathrm{eq}}=0.025+\alpha_{\mathrm{m}}\left(T-T_{\mathrm{g}, \mathrm{m}}\right)\left(1-\phi_{\mathrm{p}}\right)+\alpha_{\mathrm{p}}\left(T-T_{\mathrm{g}, \mathrm{p}}\right) \phi_{\mathrm{p}}
$$

Here, $\alpha$ is the thermal expansion coefficient, $T_{\mathrm{g}}$ the glasstransition temperature, and $\phi_{\mathrm{p}}$ the volume fraction of polymer. The subscripts $\mathrm{m}$ and $\mathrm{p}$ refer to the monomer and polymer, respectively. It is assumed that the fractional free volume at the glass-transition temperature is 0.025 , the free volume of the monomer and polymer are ideally additive, and the free volume varies linearly with temperature above the glasstransition temperature. The volume fraction of the polymer is directly related to the conversion ${ }^{23}$

$$
\phi_{\mathrm{p}}=\frac{x\left(1-\varepsilon_{\mathrm{v}}\right)}{1-x \varepsilon_{\mathrm{v}}}
$$

with $x$ the monomer conversion and $\varepsilon_{\mathrm{v}}$ the volume contraction factor, which is defined by ${ }^{25}$

$$
\varepsilon_{\mathrm{v}}=x\left(1-\frac{\rho_{\mathrm{m}}}{\rho_{\mathrm{p}}}\right)
$$

with $\rho_{\mathrm{m}}$ and $\rho_{\mathrm{p}}$ the density of the monomer and polymer, respectively.
The termination rate also includes the reaction diffusion limitation, which leads to the termination rate constant described as ${ }^{23}$

$$
k_{\mathrm{t}}=k_{\mathrm{t} 0}\left[1+\left(\frac{1}{R\left(\frac{k_{\mathrm{p}}}{k_{\mathrm{p} 0}}\right)+\exp \left[-A\left(\frac{1}{v_{\mathrm{f}}}-\frac{1}{v_{\mathrm{f}, \mathrm{ct}}}\right)\right]}\right)\right]^{-1}
$$

in which $k_{\mathrm{t} 0}$ is the initial termination rate constant, $R$ a proportionality constant, $A$ an adjustable parameter, and $v_{\mathrm{f}, \mathrm{ct}}$ the critical free volume at which termination becomes diffusion-controlled. The resistance to translational diffusion is neglected because in a cross-linking system, translational diffusion of the polymer chains is negligible from the start of the reaction. ${ }^{26}$

In order to solve the set of equations, the initiator efficiency $f$ in eq 7 has to be determined. The efficiency decreases as a function of conversion because of the "cage effect", resulting in more recombination of free radicals. ${ }^{26}$ The recombination reaction is shown in eq 22 . The free radical pair reacts to form a nonreactive molecule, at the termination rate for recombination, $k_{\mathrm{tr}}$.

$$
\mathrm{R}^{\bullet}+\mathrm{R}^{\bullet} \stackrel{k_{\mathrm{tr}}}{\longrightarrow} 2 \mathrm{R}_{\text {dead }}
$$

The recombination process involves the diffusion of small radical molecules in the reaction mixture. Rather than separately modeling this recombination process, it is taken into account via a reduction of the initiator efficiency. Therefore, the effect of conversion on the initiator efficiency is described similar to the propagation rate. Adapting eq 16 for the initiator efficiency in eq 7 leads to

$$
f=\frac{1}{1+\exp \left[C\left(\frac{1}{v_{\mathrm{f}}}-\frac{1}{v_{\mathrm{f}, \mathrm{ff}}}\right)\right]}
$$

in which the initiator efficiency at the beginning of the reaction is assumed to be $1, C$ is an adjustable parameter, and $v_{\mathrm{f}, \mathrm{cf}}$ is the critical free volume at which the initiator efficiency becomes diffusion-controlled. The adjustable parameters $A, B$, and $C$ represent the rate at which the reaction rate constants and the initiator efficiency decrease with increasing conversion, which are used as fitting parameters by Anseth and Bowman. ${ }^{23}$ In the present work, these adjustable parameters are taken equal to 1 $(A=B=C=1)$ in the implementation of the model to study the predictive capabilities with respect to changing process conditions.

2.2. Modeling Glass-Transition Temperature. The glass-transition temperature $T_{\mathrm{g}}$ is linked to the monomer conversion $x$, using a model developed by Hale et al. ${ }^{27}$ The most important advantage of this approach is the use of only one adjustable parameter. This model was adapted from a model developed by Pascault and Williams ${ }^{28}$ and is based on DiBenedetto's equation. ${ }^{29,30}$ DiBenedetto's equation is derived using the principle of corresponding states with an uncrosslinked polymer as a reference state and relates the shift in $T_{\mathrm{g}}$ to the extent of reaction for cross-linking polymers using ${ }^{29}$

$$
\frac{T_{\mathrm{g}}-T_{\mathrm{g}_{0}}}{T_{\mathrm{g}_{0}}}=\frac{\frac{\varepsilon_{\mathrm{x}}}{\varepsilon_{\mathrm{m}}}-\left(\frac{F_{\mathrm{x}}}{F_{\mathrm{m}}}\right) x}{1-\left(1-\frac{F_{\mathrm{x}}}{F_{\mathrm{m}}}\right) x}
$$


in which $T_{\mathrm{g}_{0}}$ is the glass-transition temperature of the uncrosslinked polymer, for which we use the glass-transition temperature of the uncured resin, ${ }^{31} \varepsilon_{\mathrm{x}} / \varepsilon_{\mathrm{m}}$ is the ratio of lattice energies, and $F_{\mathrm{x}} / F_{\mathrm{m}}$ is the ratio of segmental mobilities. The subscripts $\mathrm{x}$ and $\mathrm{m}$ denote the cross-linked and uncrosslinked polymers, respectively. In the case of full conversion $(x$ $=1$ ), eq 24 gives

$$
\frac{\left(\varepsilon_{\mathrm{x}} / \varepsilon_{\mathrm{m}}\right)}{\left(F_{\mathrm{x}} / F_{\mathrm{m}}\right)}=\frac{T_{\mathrm{g}_{\infty}}}{T_{\mathrm{g}_{0}}}
$$

in which $T_{\mathrm{g}_{\infty}}$ is the glass-transition temperature of the polymer at complete conversion. Introducing this in eq 24 and stating that $F_{\mathrm{x}} / F_{\mathrm{m}}=\lambda$ leads to the model developed by Pascault and Williams ${ }^{28}$

$$
\frac{T_{\mathrm{g}}-T_{\mathrm{g}_{0}}}{T_{\mathrm{g}_{\infty}}-T_{\mathrm{g}_{0}}}=\frac{\lambda x}{1-(1-\lambda) x}
$$

Based on Couchman's approach, ${ }^{32}$ using entropic considerations, the ratio $\lambda$ can be considered as ${ }^{28}$

$$
\lambda=\frac{\Delta C_{p_{\infty}}}{\Delta C_{p_{0}}}
$$

in which $\Delta C_{\mathrm{p}_{\infty}}$ and $\Delta C_{\mathrm{p}_{0}}$ are the isobaric heat capacities of the polymer at complete conversion and of the uncured resin, respectively. For systems that do not reach a monomer conversion of $100 \%(x=1)$, this model was adapted by Hale et al., ${ }^{27}$ which describes the link between monomer conversion and $T_{\mathrm{g}}$ using

$$
\frac{T_{\mathrm{g}}-T_{\mathrm{g}_{0}}}{T_{\mathrm{g}_{\mathrm{M}}}-T_{\mathrm{g}_{0}}}=\frac{\lambda^{\prime} x^{\prime}}{1-\left(1-\lambda^{\prime}\right) x^{\prime}}
$$

in which $T_{g_{M}}$ is now the glass-transition temperature of the polymer at the maximum monomer conversion of the resin studied. The correction for incomplete conversion in $x$ and $\lambda$ is done using

$$
x^{\prime}=\frac{x}{x_{\mathrm{M}}}, \text { and } \lambda^{\prime}=\frac{\Delta C_{\mathrm{p}_{\mathrm{M}}}}{\Delta C_{\mathrm{p}_{0}}}
$$

respectively, where the subscript $M$ denotes maximum conversion of the resin and subscript 0 denotes the uncured resin. The conversion as a function of glass-transition temperature is described using $\lambda^{\prime}$ as a fitting parameter.

2.3. Yield Kinetics. To describe the rate and temperature dependence of the yield stress calculated from tensile measurements, Eyring's activation flow theory is used. ${ }^{33}$ The yield stress as a function of temperature and strain rate is described by

$$
\sigma_{\mathrm{y}}(\dot{\varepsilon}, T)=\frac{k T}{V^{*}} \sinh ^{-1}\left(\frac{\dot{\varepsilon}}{\dot{\varepsilon}_{0}} \exp \left(\frac{\Delta U}{R T}\right)\right)
$$

where $V^{*}$ is the activation volume, $\dot{\varepsilon}_{0}$ the rate factor, $\Delta U$ the activation energy, $R$ the universal gas constant, $k$ the Boltzmann's constant, and $T$ the absolute temperature.

\section{MATERIALS AND METHODS}

3.1. Materials. In this work, a methacrylate monomer, bisphenolA-ethoxylated dimethacrylate (SR540, $M_{\mathrm{n}}=572 \mathrm{~g} / \mathrm{mol}$ ), supplied by
Sartomer, Arkema Group, and a photoinitiator, 2,2-dimethoxy-2phenylacetophenone (Irgacure $651, M_{\mathrm{n}}=256 \mathrm{~g} / \mathrm{mol}$ ), are used. The chemical structures are shown in Figure 1. The photoinitiator is added in powder form in an amount of 0.3 and $3 \mathrm{wt} \%$ and dissolved into the monomer by sonication to create the UV-curing resin.

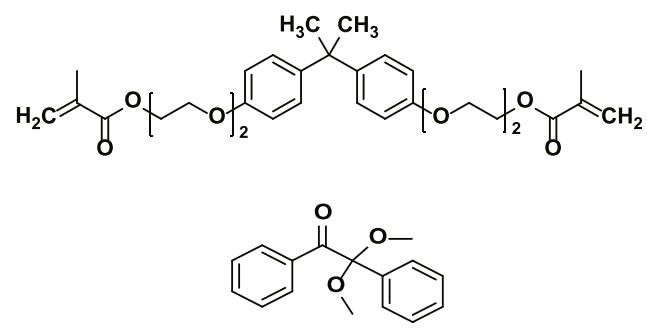

Figure 1. Chemical structure of the SR540 monomer and of the Irgacure 651 photoinitiator.

3.2. Sample Preparation. The UV-curing resin is applied on a silicon wafer and a spin coater is used to obtain a homogeneous layer with a defined thickness. A spinning speed of $357 \mathrm{rpm}$ for $30 \mathrm{~s}$ is used to obtain a layer thickness of approximately $100 \mu \mathrm{m}$. The resin is then $\mathrm{UV}$-cured in an inert atmosphere to avoid oxygen inhibition as described in our previous study. ${ }^{34} \mathrm{~A}$ first irradiation of $1.5 \mathrm{~s}$ is done to obtain the desired dog-bone-shaped samples. The samples are cured under UV light intensities ranging from 2 to $8 \mathrm{~mW} / \mathrm{cm}^{2}$ with an LED light (wavelength $365 \mathrm{~nm}$, LED Cube 100, Hönle UV Technologies). The light intensity at the sample position is uniform as measured with a UV-meter. Next, the uncured resin is washed for $4 \mathrm{~min}$ with ethanol and dried with nitrogen. The dog-bone-shaped samples are successively UV and thermally post-cured. UV post-curing is performed at the same intensities in an inert atmosphere for different curing times. Thermal post-curing is eventually done in an oven at $150{ }^{\circ} \mathrm{C}$ for $30 \mathrm{~min}$.

3.3. Material Characterization. The monomer conversion is determined using FTIR spectroscopy analysis (Spectrum Two FTIR Spectrometer, PerkinElmer), equipped with an attenuated total reflectance (ATR) module. FTIR measurements are performed in the range of wavenumbers from 4000 to $400 \mathrm{~cm}^{-1}$ while intermittently curing the resin in situ. A box has been fabricated to create the inert atmosphere needed during the photopolymerization reaction. ${ }^{34}$ A portable LED UV-lamp is connected to a controller (bluepoint LED eco, wavelength $365 \mathrm{~nm}$, Hönle UV Technologies) and fixed on top of the box. The light intensity at the sample position is uniform as measured with a UV-meter. Tests are performed on samples $100 \mu \mathrm{m}$ thick, which guarantees that no gradient in curing is present throughout the layer thickness. The layer of the liquid resin is placed on the ATR crystal and the box, equipped with an inlet tube and outflow hole, is positioned on the spectrometer and flushed with nitrogen for $3 \mathrm{~min}$. The resin is then intermittently illuminated for the desired total time under UV light intensities ranging from 2 to 59 $\mathrm{mW} / \mathrm{cm}^{2}$, and absorbance spectra are collected after each pulse of light. In particular, a pulse duration of $0.1 \mathrm{~s}$ is used to accurately follow the evolution in time of monomer consumption. The conversion, $\alpha(t)$, is determined using the second derivative method by $^{35}$

$$
\alpha(t)=\frac{\left[\frac{A_{1637}^{\prime \prime}}{A_{1608}^{\prime \prime}}\right]_{0}-\left[\frac{A_{1637}^{\prime \prime}}{A_{1608}^{\prime \prime}}\right]_{t}}{\left[\frac{A_{1637}^{\prime \prime}}{A_{1608}^{\prime \prime}}\right]_{0}} \cdot 100
$$

where $\left[A_{1637}{ }^{\prime \prime} / A_{1608}{ }^{\prime \prime}\right]_{0}$ and $\left[A_{1637}{ }^{\prime \prime} / A_{1608}{ }^{\prime \prime}\right]_{t}$ represent the ratio of the second derivative of the methacrylate double-bond at $1637 \mathrm{~cm}^{-1}$ and the internal reference at $1608 \mathrm{~cm}^{-1}, 36$ before and after UV exposure for time $t$. All the measurements are repeated at least two times and the average values are shown. Error bars are smaller than the symbols and therefore omitted. 


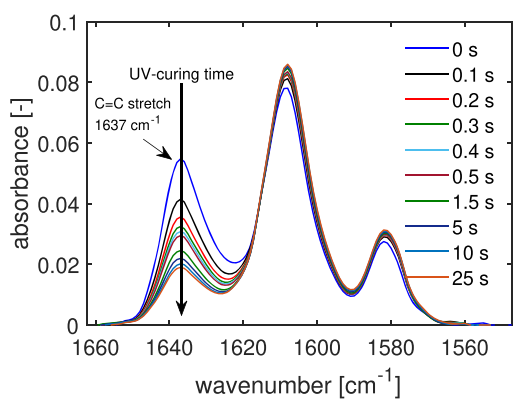

(a)

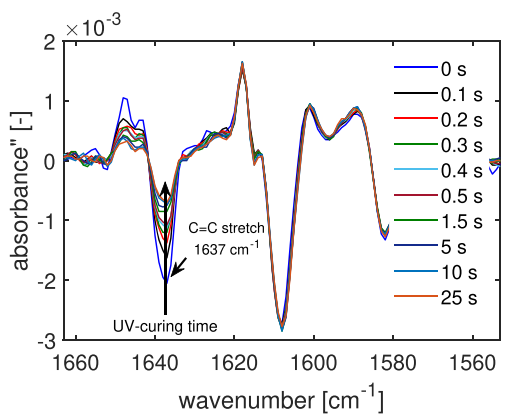

(b)

Figure 2. Evolution of the $\mathrm{C}=\mathrm{C}$ stretch peak at $1637 \mathrm{~cm}^{-1}$ during UV-curing of the methacrylate resin: absorbance spectra acquired in ATR mode (a) and second derivative of the absorbance (b) as a function of wavenumber.

The densities of the liquid resin and UV-cured sample are measured at room temperature by using a pycnometer (AccuPyc 1330 , Micromeritics), from which the volume contraction factor, $\varepsilon_{v}$, is determined using eq 20.

Dynamic mechanical thermal analysis (DMTA) is employed to study the effect of process conditions on the glass-transition temperature, $T_{\mathrm{g}}$. Dog-bone-shaped samples of about $100 \mu \mathrm{m}$ thickness and $2.5 \mathrm{~mm}$ width are tested using a TA Instruments Q800 DMA, at a frequency of $1 \mathrm{~Hz}$, in a temperature range from -50 to $150{ }^{\circ} \mathrm{C}$ with a heating rate of $3{ }^{\circ} \mathrm{C} / \mathrm{min}$. A strain amplitude of $0.1 \%$ and preload of $0.01 \mathrm{~N}$ are applied. The storage and loss modulus are recorded as functions of temperature, and the $T_{\mathrm{g}}$ is defined as the maximum in $\tan (\delta)$.

Tensile tests are performed to study the effect of curing time and UV light intensity on the mechanical properties of the UV-cured methacrylate resin. Room temperature uniaxial tensile tests are performed on a microtensile stage (TST350 Linkam Scientific) equipped with a $200 \mathrm{~N}$ load cell. The dimensions of the tensile specimens (length $30 \mathrm{~mm}$, thickness $0.1 \mathrm{~mm}$, and width $2.5 \mathrm{~mm}$ ), corresponding to the photomask design, are based on ASTM standard D638 type I. Tensile measurements at different temperatures, ranging from -10 to $80{ }^{\circ} \mathrm{C}$, are performed using a Zwick/Roell testing machine, equipped with a $1 \mathrm{kN}$ load cell and a temperature-controlled chamber. The tests are performed at strain rates in the range from 5.5 $\times 10^{-5}$ to $1.9 \times 10^{-3} \mathrm{~s}^{-1}$ and repeated at least two times.

\section{RESULTS AND DISCUSSION}

4.1. Monomer Conversion. The first step to characterize the UV-curing of the methacrylate resin is to investigate the effect of curing time on the monomer conversion. Additionally, the polymerization kinetics are described with the model presented in Section 2.1. The predictive capability of the model is further tested by studying the effect of UV light intensity and initiator concentration on the conversion.

4.1.1. Effect of Curing Time. The monomer conversion is determined by using FTIR measurements in ATR mode, in which the absorbance as a function of wavenumber is recorded. In Figure $2 \mathrm{a}$, the evolution of the $\mathrm{C}=\mathrm{C}$ double-bond peak at $1637 \mathrm{~cm}^{-1}$ as a function of the wavenumber is reported for a selection of UV-curing times. It is clear that the number of double bonds decreases with increasing curing time. The monomer conversion is determined using the second derivative method (Figure 2b), as described in Section 3.3.

The monomer conversion as a function of curing time and the model fit are shown in Figure 3. The data refer to the curing that occurs at the bottom of a $100 \mu \mathrm{m}$ thick layer. As the exposure time increases, the conversion of the double bonds increases to a final value of $73 \%$. First, the ratio $k_{\mathrm{p} 0} / k_{\mathrm{t} 0} 0.5$ is calculated from the steepest slope of the initial rate of polymerization (eq 12) and the model is then fitted to the

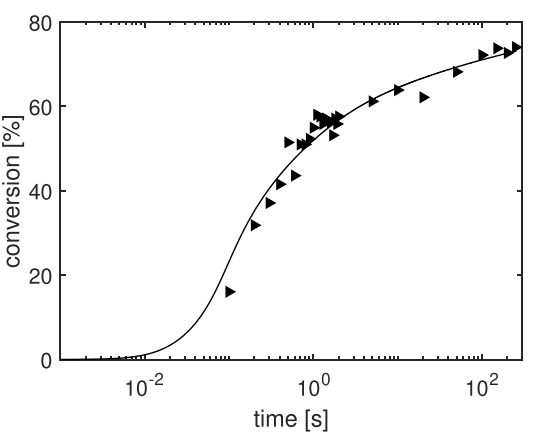

Figure 3. Monomer conversion as a function of curing time for a resin with 3 wt \% of photoinitiator irradiated at a light intensity of $8 \mathrm{~mW} /$ $\mathrm{cm}^{2}$. The markers represent the experimental results and the solid line the model fit.

experimental data. Table 1 summarizes the parameters used in the model. Each fitting parameter represents a physical phenomenon during the photopolymerization. For instance, the critical conversion for termination, $x_{\mathrm{crt}}$ is assumed to be equal to zero, because in cross-linked systems the termination rate is diffusion-controlled from the beginning of the

Table 1. Model Parameters for Polymerization Kinetics

\begin{tabular}{|c|c|c|c|}
\hline parameter & value & unit & references \\
\hline$k_{\mathrm{p} 0} / k_{\mathrm{t} 0}^{0.5}$ & 2.9921 & {$\left[\mathrm{~m}^{1.5} \mathrm{~mol}^{-0.5} \mathrm{~s}^{-0.5}\right]$} & $\begin{array}{l}\text { determined } \\
\text { experimentally }\end{array}$ \\
\hline$\varepsilon_{\mathrm{v}}$ & 0.0523 & {$[-]$} & $\begin{array}{l}\text { determined } \\
\text { experimentally }\end{array}$ \\
\hline$A$ & 1 & {$[-]$} & fixed a priori \\
\hline$B$ & 1 & {$[-]$} & fixed a priori \\
\hline C & 1 & {$[-]$} & fixed a priori \\
\hline$R$ & 0.02 & {$[-]$} & $\begin{array}{l}\text { Anseth, Wang, and } \\
\text { Bowman }\end{array}$ \\
\hline$\alpha_{\mathrm{m}}$ & $5 \times 10^{-4}$ & {$\left[{ }^{\circ} \mathrm{C}^{-1}\right]$} & Anseth and Bowman ${ }^{23}$ \\
\hline$\alpha_{\mathrm{p}}$ & $75 \times 10^{-6}$ & {$\left[{ }^{\circ} \mathrm{C}^{-1}\right]$} & Anseth and Bowman ${ }^{23}$ \\
\hline$T_{\mathrm{g}, \mathrm{m}}$ & -42 & {$\left[{ }^{\circ} \mathrm{C}\right]$} & Stansbury $^{37}$ \\
\hline$T_{\mathrm{g}, \mathrm{p}}$ & 108 & {$\left[{ }^{\circ} \mathrm{C}\right]$} & $\begin{array}{l}\text { determined } \\
\text { experimentally }\end{array}$ \\
\hline$T$ & 25 & {$\left[{ }^{\circ} \mathrm{C}\right]$} & process condition \\
\hline$\lambda$ & $365 \times 10^{-9}$ & {$[\mathrm{~m}]$} & process condition \\
\hline$\phi$ & 0.6 & {$[-]$} & Boddapati $^{18}$ \\
\hline$\varepsilon$ & 15 & {$\left[\mathrm{~m}^{2} \mathrm{~mol}^{-1}\right]$} & Boddapati $^{18}$ \\
\hline$k_{\mathrm{t} 0}$ & $1 \times 10^{5}$ & {$\left[\mathrm{~m}^{3} \mathrm{~mol}^{-1} \mathrm{~s}^{-1}\right]$} & adjustable parameter \\
\hline$x_{\text {crp }}$ & 0.19 & {$[-]$} & adjustable parameter \\
\hline$x_{\mathrm{crt}}$ & 0 & {$[-]$} & fixed a priori \\
\hline$x_{\mathrm{crf}}$ & 0.58 & {$[-]$} & adjustable parameter \\
\hline
\end{tabular}




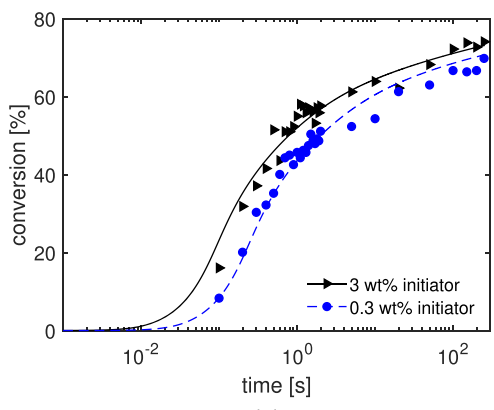

(a)

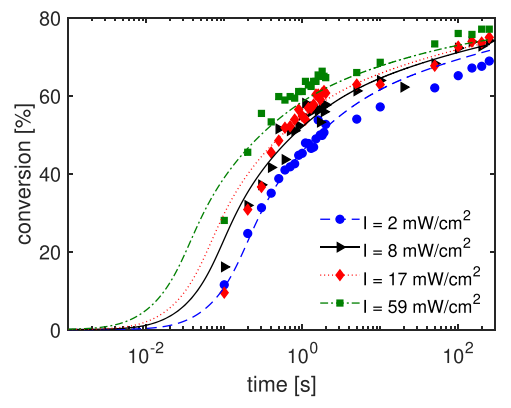

(b)

Figure 4. Effect of process conditions on polymerization kinetics: (a) model fit for formulations with 3 wt $\%$ of the initiator and prediction for 0.3 wt $\%$ of the initiator for the resin irradiated at a light intensity of $8 \mathrm{~mW} / \mathrm{cm}^{2}$; (b) polymerization kinetics for several UV light intensities. Model fit is shown for an intensity of $8 \mathrm{~mW} / \mathrm{cm}^{2}$, and model predictions are shown for intensities of 2,17 , and $59 \mathrm{~mW} / \mathrm{cm}^{2}$. The markers represent the measurements and the lines the model descriptions.

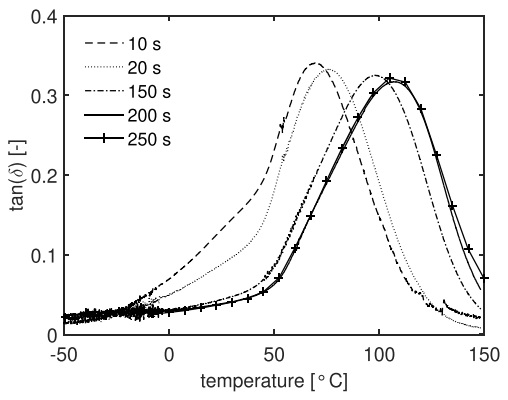

(a)

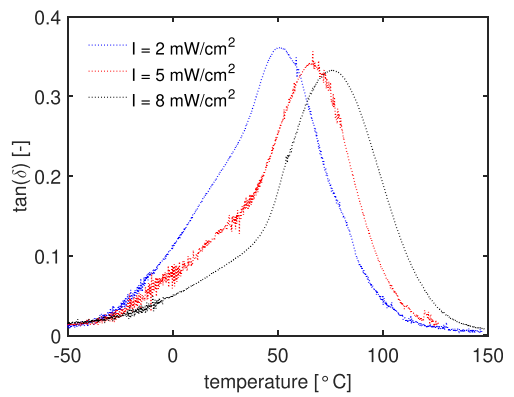

(b)

Figure 5. (a) $\tan (\delta)$ as a function of temperature for a resin (with $3 \mathrm{wt} \%$ of the initiator) cured at a light intensity of $8 \mathrm{~mW} / \mathrm{cm}^{2}$ for a selection of UV postcuring times and (b) effect of light intensity on samples UV postcured for $20 \mathrm{~s}$.

polymerization reaction. Moreover, as expected, as the radical molecules are smaller in size as compared to the growing polymer chains, the critical conversion for initiator efficiency turns out to be higher than the one for propagation. The sensitivity of the model predictions to $k_{\mathrm{p} 0} / k_{\mathrm{t} 0}{ }^{0.5}$ ratio, and the variation of $k_{\mathrm{p}}, k_{\mathrm{t}}$ and efficiency $f$ with the degree of conversion are shown in the Supporting Information, Figures S1 and S2. The conversion values at which the parameters start decreasing are determined by the critical conversion values. The curves in Figure 3 are in good agreement with theory and experimental results in literature. ${ }^{23,26}$

4.1.2. Effect of Process Conditions. The rate of polymerization reactions is typically affected by different process conditions. The effect of initiator concentration and UV light intensity is studied and predicted with the developed model. To validate the monomer conversion predictions, FTIR measurements are carried out. The effect of the initiator concentration is shown in Figure $4 \mathrm{a}$. The conversion is measured for formulations with 0.3 and $3 \mathrm{wt} \%$, keeping all the other parameters constant. It is clear that a decrease in concentration of the initiator leads to a decrease in polymerization rate. The model is fitted for the $3 \mathrm{wt} \%$ composition and the prediction for the formulation with $0.3 \mathrm{wt}$ $\%$ initiator is made by changing only the initial concentration. The experimental results are in quantitative agreement with the prediction. The monomer conversion at long curing times is slightly overpredicted. This small deviation from the experimental data may indicate that the vitrification behavior changes with initiator concentration. The different vitrification mechanism would change the critical conversion at which propagation and initiator efficiency ( $x_{\mathrm{crp}}$ and $x_{\mathrm{cr}}$, respectively) become diffusion-controlled. For instance, a lower concentration of initiator in the network could lower both $x_{\mathrm{crp}}$ and $x_{\mathrm{cr}}$, thereby decreasing the propagation rate and leading to a lower final conversion value. The effect of changing $x_{\mathrm{crp}}$ and $x_{\mathrm{crf}}$ on the prediction of monomer conversion is shown in the Supporting Information, Figure S3.

The effect of light intensity is shown in Figure $4 \mathrm{~b}$. The conversion is measured for light intensities of $2,8,17$, and 59 $\mathrm{mW} / \mathrm{cm}^{2}$. A composition with $3 \mathrm{wt} \%$ of the initiator is used and all the other process conditions are kept constant. As expected, increasing the light intensity increases the monomer conversion. Similar to the effect of the initiator concentration, the light intensity clearly affects the polymerization rate at short curing times, as also observed in literature. ${ }^{2}$ Moreover, the final conversion slightly increases with increasing light intensity. The conversion increases from a final value of $67-$ $77 \%$ for intensities of 2 and $59 \mathrm{~mW} / \mathrm{cm}^{2}$, respectively. The model is fitted to the light intensity of $8 \mathrm{~mW} / \mathrm{cm}^{2}$ and the conversion is predicted for the other intensities. The trend of increasing monomer conversion for higher intensities is also captured by the model predictions. However, the experimental data deviates from the predictions around a curing time of 0.1 s. This inaccuracy may be caused by the presence of molecular oxygen in the liquid resin, which leads to a delay in the polymerization. Moreover, for the highest intensity, the model starts levelling off slightly earlier than the experimental results. A possible reason for this small discrepancy is that the critical conversions at which the propagation rate constant and initiator efficiency start decreasing can be higher for a higher intensity. This phenomenon might be caused by the creation of excess free volume during the faster reaction, which makes it 


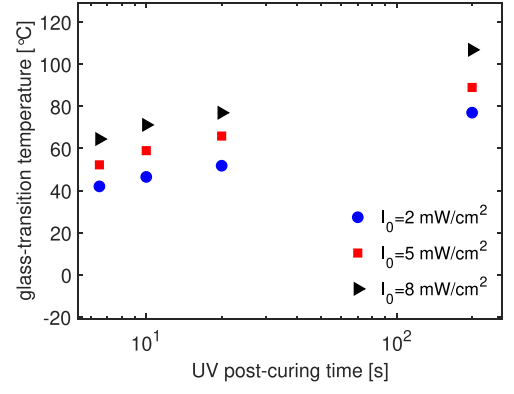

(a)

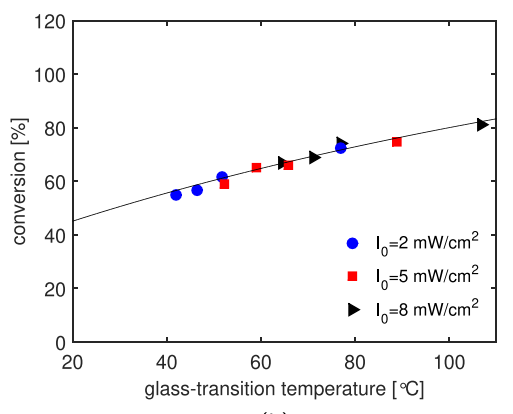

(b)

Figure 6. Effect of UV light intensity: glass-transition temperature as a function of irradiation time for samples cured under different light intensities (a) and monomer conversion as a function of glass-transition temperature for samples UV postcured for 6.5, 10, 20, and 200 s. The markers are the experimental results and the line is the prediction based on the Hale model (b).

easier for the molecules to diffuse in the network. ${ }^{38}$ Moreover, higher intensity causes an increase of temperature in the reacting environment. ${ }^{39-42}$ Suzuki et al. ${ }^{42}$ have demonstrated that the temperature increases dramatically $\left(40{ }^{\circ} \mathrm{C}\right)$ during the polymerization of methyl methacrylate resins. Tripathy et al. ${ }^{41}$ have studied the effect of light intensity on the photopolymerization of (meth)acrylate systems. They observed an increase in both polymerization rate and temperature with an increase in UV light intensity. Therefore, the higher experimental conversion values could be explained by the higher local temperature, which has not been taken into account in the model. Previous research ${ }^{39}$ shows that increasing the local temperature increases the mobility of the reacting species, leading to an increase in the maximum polymerization rate, and therefore higher final conversions. In case of low intensity, increasing the exposure time does not increase the conversion any further. In these systems, the lower mobility diffusion is more the limiting factor, which leads to incomplete conversion. Therefore, in each system the monomer conversion is probably caused by a combination of both photo and thermal effects.

4.2. Glass-Transition Temperature. 4.2.1. Effect of Process Conditions. The DMTA curves for the methacrylate resin UV postcured at various times and intensities are shown in Figure 5. All the samples are first UV-cured for $1.5 \mathrm{~s}$ and successively UV postcured, as explained in Section 3.2. Figure 5a shows $\tan (\delta)$ as a function of temperature for a selection of UV postcured samples cured at an intensity of $8 \mathrm{~mW} / \mathrm{cm}^{2}$. The maximum of the peak shifts to higher temperatures, and therefore a higher glass-transition temperature is reached with increasing irradiation time. The results show that there is an increase in $T_{\mathrm{g}}$ with postcuring times and after $200 \mathrm{~s}$ a maximum is reached. A similar behavior has been seen for acrylate systems. ${ }^{34}$ Figure $5 \mathrm{~b}$ shows the DMTA results for samples UV postcured for $20 \mathrm{~s}$ under light intensities of 2, 5, and $8 \mathrm{~mW} / \mathrm{cm}^{2}$. It is clear that an increase of intensity leads to an increase in $T_{\mathrm{g}}$. Moreover, Figure 5 shows the presence of a small shoulder in the $\tan (\delta)$ of samples cured with a low curing time and low light intensity, which disappears when further curing is performed. It is caused by the heterogeneous nature of the polymer network at low degrees of conversion.

Figure 6a presents the results of the glass-transition temperature as a function of UV postcuring time (6.5, 10, 20 , and $200 \mathrm{~s}$ ) of the three systems studied. Clearly, the overall trend does not change with changes in light intensity. However, in accordance with the monomer conversion, when the resin is cured at a lower intensity, a lower $T_{\mathrm{g}}$ is observed. A similar behavior has been reported by Unterbrink and Muessner. ${ }^{43}$ They studied the effect of light intensity on the mechanical properties, and they observed a reduction of strength and modulus with decreasing intensity, for the same exposure time. Previous studies have also shown that the mechanical properties do not change if the material is irradiated with the same dose (intensity multiplied by curing time) $){ }^{13}$ Interestingly, the behavior seems to be different in our systems. For instance, to obtain a polymer with a $T_{\mathrm{g}}$ of approximately $65{ }^{\circ} \mathrm{C}$, the sample has to be cured for $6.5 \mathrm{~s}$ at a light intensity of $8 \mathrm{~mW} / \mathrm{cm}^{2}$ or for $20 \mathrm{~s}$ at $5 \mathrm{~mW} / \mathrm{cm}^{2}$, corresponding to a total energy level of 52 and $100 \mathrm{~mJ} / \mathrm{cm}^{2}$, respectively (see Figure $6 \mathrm{~b}$ ). Therefore, in order to obtain the same ultimate properties, a higher energy level is required if the resin is irradiated at lower light intensity. A reason for this behavior might be that the increase in intensity increases the maximum temperature reached during polymerization, which provides more molecular mobility, higher conversion, and therefore a higher glass-transition temperature. ${ }^{11,40}$

Figure $6 \mathrm{a}$ shows that the glass-transition temperature as a function of UV postcuring times has a strong similarity to the monomer conversion, which also shows an increase to a maximum at long curing times. The similarity in trends indicates that there is a strong connection between conversion and $T_{\mathrm{g}}$. Figure $6 \mathrm{~b}$ shows the conversion as a function of the glass-transition temperature, including a fit of the model described in Section 2.2. The figure shows an increase in $T_{\mathrm{g}}$ with increasing conversion, which is captured very well by the model developed by Hale et al. ${ }^{27}$ and seems independent of the light intensity. The model parameters used for the fit are stated in Table 2. A similar observation has been shown in the work of Lovell et al. ${ }^{14}$ for a common dimethacrylate dental resin formulation (75/25 wt \% bis-GMA/TEGDMA), in which a unique fit describes the glass-transition temperature as a function of conversion for samples cured under different light intensities and light sources.

Table 2. Model Parameters (Eq 28) for Glass-Transition Temperature

\begin{tabular}{ccll} 
parameter & value & unit & \multicolumn{1}{c}{ references } \\
$T_{\mathrm{g}_{0}}$ & -42 & {$\left[{ }^{\circ} \mathrm{C}\right]$} & Stansbury $^{37}$ \\
$T_{\mathrm{g}_{\mathrm{M}}}$ & 108 & {$\left[{ }^{\circ} \mathrm{C}\right]$} & determined experimentally \\
$x_{\mathrm{M}}$ & 82 & {$[\%]$} & determined experimentally \\
$\lambda^{\prime}$ & 0.59 & {$[-]$} & adjustable parameter
\end{tabular}




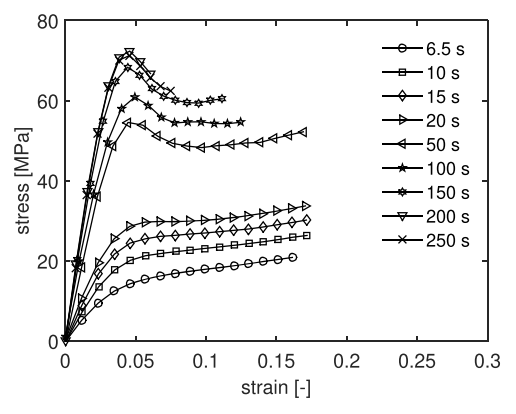

(a)

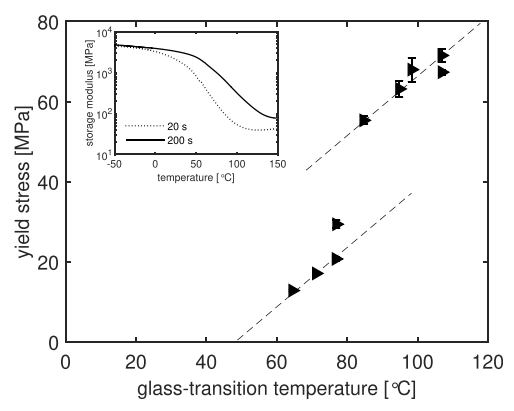

(b)

Figure 7. (a) Stress-strain response for UV postcured samples measured at a strain rate of $1.9 \times 10^{-3} \mathrm{~s}^{-1}$ at $23^{\circ} \mathrm{C}$. (b) Yield stress as a function of glass-transition temperature. The storage modulus as a function of temperature for samples UV postcured for 20 and $200 \mathrm{~s}$ is shown in the inset. All the samples, having $3 \mathrm{wt} \%$ of the initiator, are cured at a light intensity of $8 \mathrm{~mW} / \mathrm{cm}^{2}$.

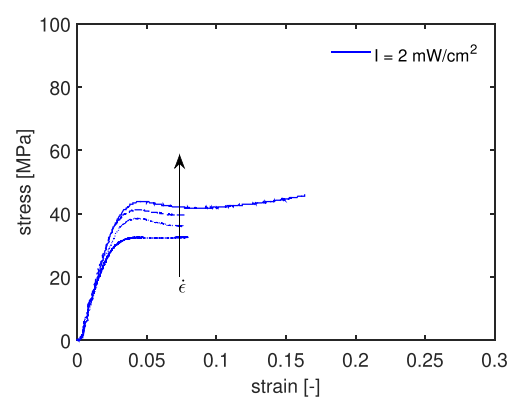

(a)

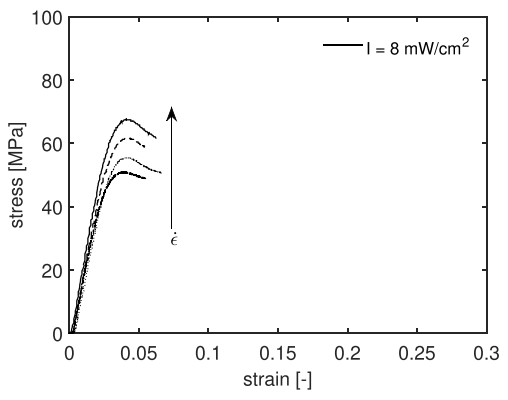

(c)

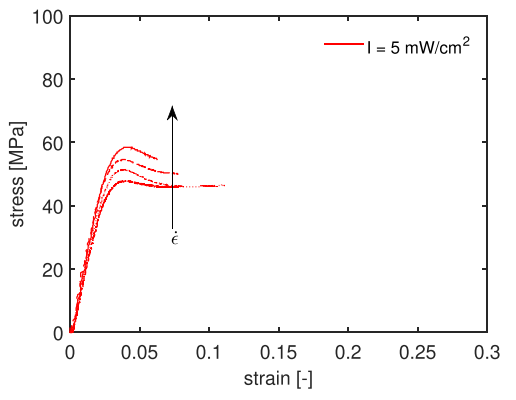

(b)

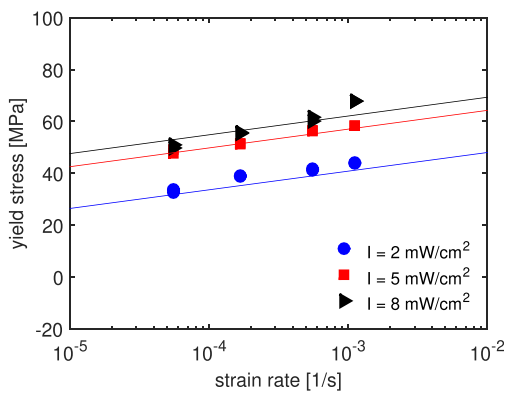

(d)

Figure 8. Effect of intensity on the mechanical properties for formulations with $3 \mathrm{wt} \%$ of the initiator: stress-strain response for samples UV postcured for $200 \mathrm{~s}$ at a light intensity of (a) 2, (b) 5 , and (c) $8 \mathrm{~mW} / \mathrm{cm}^{2}$. The samples are measured at room temperature, for constant strain rates ranging from $5.5 \times 10^{-5}$ to $1.1 \times 10^{-3} \mathrm{~s}^{-1}$. (d) Yield stress vs applied strain rate for samples cured under different light intensities; the markers are the experimental results and the lines the fitting based on the Eyring equation (eq 30).

4.3. Mechanical Properties. 4.3.1. Effect of Curing Time. The effect of UV postcuring time on the tensile behavior of the methacrylate resin is shown in Figure 7. All the samples are UV-cured for $1.5 \mathrm{~s}$ and successively postcured for different times as described in Section 3.2. Figure 7a shows the stressstrain response of a selection of cured samples tested at room temperature at a constant strain rate of $1.9 \times 10^{-3} \mathrm{~s}^{-1}$. As expected, the overall stress level increases as the UV postcuring time increases. The mechanical response follows a similar trend as the glass-transition temperature (Figure 5a): the yield stress strongly increases with curing time. At $200 \mathrm{~s}$ of UV postcuring time, the yield stress reaches a maximum value of approximately $70 \mathrm{MPa}$. Figure $7 \mathrm{~b}$ presents the evolution of yield stress as a function of glass-transition temperature. Within a specific $T_{\mathrm{g}}$ range, the data show a linear relation between yield stress and $T_{g}$, similar to that observed in literature for epoxy and methacrylate resins. ${ }^{44,45}$ However, samples having a glass-transition temperature of around $80{ }^{\circ} \mathrm{C}$ present a jump in the yield stress, which can be explained by the fact that the samples, having different network structures because of the difference in curing time, are tested at the same temperature.

Figure $7 \mathrm{a}$ shows that samples UV postcured for less than 20 $s$ have a mechanical response in which no visible yield stress is present. This behavior is because for low curing times, the samples are characterized by low glass-transition temperatures, which are close to the tensile testing temperature. On the other hand, samples cured for longer times have a $T_{\mathrm{g}}$ far above the testing temperature; therefore, the mechanical response is not affected. This can be observed in the inset of Figure $7 \mathrm{~b}$, in which the evolution of the storage modulus as a function of temperature is shown for samples UV postcured for 20 and $200 \mathrm{~s}$. It is clear that at room temperature, the sample cured for $20 \mathrm{~s}$ is in the glass-transition region starting from $60^{\circ} \mathrm{C}$ below $T_{g}$; therefore, the tensile response of the same sample tested at room temperature shows a rubber-like behavior. On the other hand, the sample UV postcured for $200 \mathrm{~s}$ is still in the glassy region at the testing temperature. This observation explains the 
jump in mechanical response observed for the samples UV postcured for longer than $20 \mathrm{~s}$ (Figure 7a) and the two different linear relations presented in Figure $7 \mathrm{~b}$.

4.3.2. Effect of Light Intensity. To study the effect of light intensity on the ultimate mechanical properties, tensile tests are carried out on samples maximally UV-cured for $200 \mathrm{~s}$ at different intensities. This ensures that all samples are in the glassy region at room temperature. The tests are performed at room temperature with constant strain rates ranging from 5.5 $\times 10^{-5}$ to $1.1 \times 10^{-3} \mathrm{~s}^{-1}$. Stress as a function of strain for these experiments is plotted in Figure $8 \mathrm{a}-\mathrm{c}$. After the initial linear elastic region, with increasing strain, the system becomes more mobile, causing a deviation from the linear behavior. At the yield point, the mobility is so high that the plastic deformation rate equals the applied strain rate. ${ }^{46}$ At higher strain rates, this balance is achieved at higher stress, as observed in the strainrate dependence of the mechanical response, see Figure $8 \mathrm{a}-\mathrm{c}$. After yielding, depending on the cross-linked network, strain softening is observed. The amount of softening varies depending on the process conditions applied during the sample preparation. It can be observed that the strain softening is less for samples cured at low light intensity, see Figure 8a. Therefore, in these systems, the segmental chain mobility is higher, leading to a lower resistance against deformation.

The yield stress as a function of the applied strain rate for the three studied systems is plotted in Figure 8d, in which the lines are the results of the Eyring equation. In order to describe the experimental results, the set of parameters shown in Table 3 is employed. The activation energy, $\Delta U$, and activation

Table 3. Eyring Parameters

$\begin{array}{cccc}I\left[\mathrm{~mW} / \mathrm{cm}^{2}\right] & V^{*}\left[\mathrm{~nm}^{3}\right] & \dot{\varepsilon}_{0}\left[\mathrm{~s}^{-1}\right] & \Delta U[\mathrm{~kJ} / \mathrm{mol}] \\ 2 & 13 & 10 \times 10^{76} & 482 \\ 5 & 13 & 30 \times 10^{73} & 482 \\ 8 & 13 & 60 \times 10^{72} & 482\end{array}$

volume, $V^{*}$, are the same for the three systems. The rate factor $\dot{\varepsilon}_{0}$ decreases with increasing light intensity, and therefore with increasing glass-transition temperature. Samples cured at a lower light intensity display a lower yield stress, which is in accordance with the monomer conversion and glass-transition temperature evolutions reported in Figures $4 \mathrm{~b}$ and $6 \mathrm{a}$, respectively. An attempt has been made to predict the deformation kinetics for samples cured under different light intensities using the approach proposed by Parodi et al. for polyamides. ${ }^{47}$ This approach is based on the hypothesis that the distance to $T_{\mathrm{g}}$ determines the mechanical response. The decrease in glass-transition temperature for samples cured at a lower intensity can be seen as an apparent increase in the testing temperature. Therefore, the temperature $T$ in the Eyring equation (eq 30) can be modified as

$$
\tilde{T}=T+\left(T_{\mathrm{g}, 8 \mathrm{~mW} / \mathrm{cm}^{2}}-T_{\mathrm{g}, \mathrm{I}_{\mathrm{x}}}\right)
$$

where $\tilde{T}$ is the apparent temperature, $T_{\mathrm{g}, 8 \mathrm{~mW} / \mathrm{cm}^{2}}$ and $T_{\mathrm{g}, I_{\mathrm{x}}}$ are the glass-transition temperatures of the sample cured at $8 \mathrm{~mW} /$ $\mathrm{cm}^{2}$ and at lower intensity $I_{x}$, respectively. Hence, the mechanical response of samples UV-cured under different intensities would be the same if tensile tests are performed at a temperature so as to keep the distance to $T_{\mathrm{g}}$ constant. The deformation kinetics for samples cured for $200 \mathrm{~s}$ at 2 and 8 $\mathrm{mW} / \mathrm{cm}^{2}$ are shown in Figure 9a. For these specimens, tensile tests are performed at 10 and $40{ }^{\circ} \mathrm{C}$, respectively, to keep the distance to $T_{\mathrm{g}}\left(\Delta T_{\mathrm{g}}=T_{\mathrm{g}}-T=66^{\circ} \mathrm{C}\right)$ constant. The lines are the results of the original Eyring prediction (eq 30), using the model parameters shown in Table 3 at testing temperatures of 10 and $40{ }^{\circ} \mathrm{C}$. The results shown in Figure 9a seem to disagree with the hypothesis previously made. It is clear that the lowerintensity samples show a higher-yield stress compared to samples cured at $8 \mathrm{~mW} / \mathrm{cm}^{2}$ when tested at a fixed temperature difference from $T_{\mathrm{g}}$. Therefore, the influence of testing temperature is studied and the results are shown in Figure $9 \mathrm{~b}$. Tensile tests are performed at a constant strain rate, $5.5 \times 10^{-5} \mathrm{~s}^{-1}$ and at different temperatures ranging from -20 to $80{ }^{\circ} \mathrm{C}$. At very high temperatures, the temperature dependence of the yield stress flattens; this is due to the close proximity to $T_{\mathrm{g}}$. When the yield stress is plotted versus $T_{\mathrm{g}}$ $-T$ (Figure 9b), the data show a clearly different temperature dependence for the two systems studied. In particular, for a defined distance to $T_{g}$, the samples cured at a lower intensity always present a higher mechanical response.

The yield stress data follow an engineering rule

$$
\sigma_{\mathrm{y}}=a\left(T_{\mathrm{g}}-T\right)-35
$$

where $a[\mathrm{MPa} / \mathrm{K}]$ is the slope which is equal to 1.4 and 1.1 for samples UV-cured at intensities of 2 and $8 \mathrm{~mW} / \mathrm{cm}^{2}$, respectively. These slopes are similar to those found in literature for thermoset polymers. ${ }^{48,49}$ Moreover, similar to our findings, Cook et al. ${ }^{48}$ have shown that uncross-linked polymers have a higher yield stress than the corresponding cross-linked material, suggesting that the systems have different

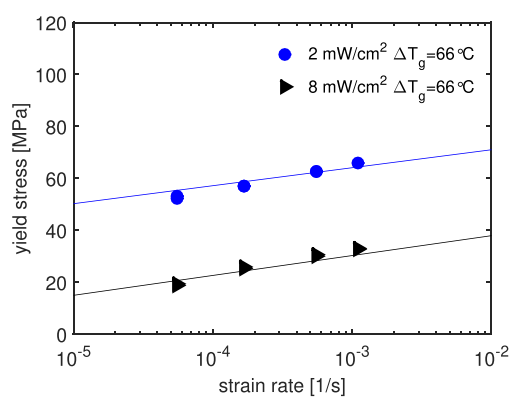

(a)

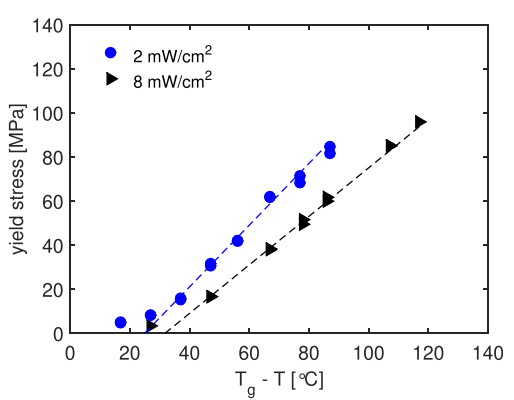

(b)

Figure 9. (a) Strain rate dependence for samples maximally UV-cured at light intensities of 2 and $8 \mathrm{~mW} / \mathrm{cm}^{2}$. Tensile tests are performed at 10 and $40{ }^{\circ} \mathrm{C}$, respectively, to keep the distance from $T_{\mathrm{g}}\left(T_{\mathrm{g}}-T=\Delta T_{\mathrm{g}}=66^{\circ} \mathrm{C}\right)$ constant, illustrating a clear temperature dependence of the yield stress. The markers are experimental results and the lines are the model predictions. (b) Yield stress as a function of $\Delta T_{\mathrm{g}}$ with testing temperature ranging from -20 to $80^{\circ} \mathrm{C}$, tested at a constant strain rate of $5.5 \times 10^{-4} \mathrm{~s}^{-1}$. 
molecular mobilities. Therefore, because of a different network structure, a unique correlation between $T_{\mathrm{g}}$ and mechanical properties cannot be found for the studied systems.

To study how the light intensity affects the cured network, a thermal postcuring treatment is performed on samples previously UV postcured for 200 s. In our previous work, ${ }^{34}$ we have shown that thermal postcuring leads to an increase in mechanical response because of the continued reaction of trapped radicals next to a thermodynamically more stable structure. The effect of thermal postcuring is shown in Figure 10. Samples cured at $8 \mathrm{~mW} / \mathrm{cm}^{2}$ are not affected by the

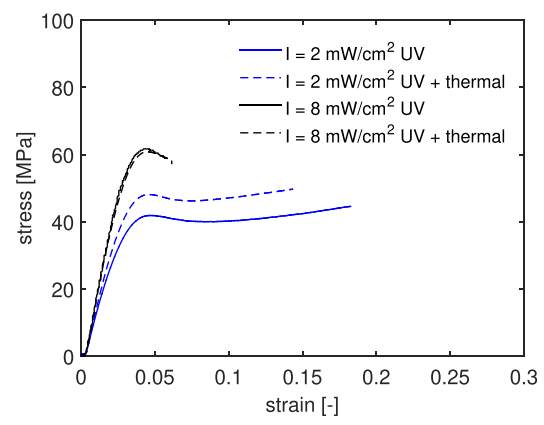

Figure 10. Effect of thermal postcuring $\left(150{ }^{\circ} \mathrm{C}\right.$ for $\left.30 \mathrm{~min}\right)$ on the mechanical response of samples UV-cured for $200 \mathrm{~s}$ under different UV light intensities. Tensile tests are performed at room temperature and at a constant strain rate of $5.5 \times 10^{-4} \mathrm{~s}^{-1}$.

thermal treatment, whereas those cured at a lower intensity, 2 $\mathrm{mW} / \mathrm{cm}^{2}$, show an increase in yield stress. This effect can be explained by the presence of dangling and uncured chains in the network of samples cured at a low intensity. These can further react when the network mobility is increased during thermal postcuring. This is in accordance with the lower $T_{\mathrm{g}}$ measured for these systems, see Figure 6a. On the other hand, samples cured at a high intensity have a denser network in which further polymerization cannot occur. Faster polymerization at a higher intensity produces shorter and more crosslinked polymers because of premature initiation in more points and faster termination of reactions. ${ }^{13}$

\section{CONCLUSIONS}

In this study, the effects of process conditions on the photopolymerization and mechanical properties of a UVcured methacrylate resin are investigated. First, the effects of curing time, light intensity, and initiator concentration on the monomer conversion are presented. The monomer conversion shows an increase with increasing curing time, reaching a plateau value after $200 \mathrm{~s}$ of irradiation. The influence on the polymerization kinetics of light intensity and initiator concentration is similar: an increase in polymerization rate is observed with increasing intensity and initiator concentration. A model is developed based on the reaction kinetics of photopolymerization that describes the experimental data. The effects of light intensity and initiator concentration are predicted within reasonable accuracy. To investigate the influence of process conditions on the mechanical properties, dynamic mechanical analysis and tensile tests are performed. A similar trend as for the monomer conversion is found: the glass-transition temperature increases with increasing curing time and UV light intensity. A unique correlation exists between the glass-transition temperature and the conversion, irrespective of the light intensity and curing time. Similarly, the yield stress increases with curing time until maximum conversion is reached. However, the UV light intensity causes structural changes that affect the yield stress. Low intensity causes the presence of unconverted and dangling chains in the UV-cured networks, which lower the glass-transition temperature and yield stress to a different extent. Therefore, the mechanical response is not determined by the distance to $T_{\mathrm{g}}$, as common in other systems. ${ }^{47}$ As a matter of fact, the resins UV-cured at various intensities show different evolutions of yield stress as a function of temperature. Finally, thermal postcuring treatments are performed on maximally cured samples. The results show an increase in yield stress only in samples UV-cured at a low intensity. This characteristic confirms the presence of dangling chains in the network that can further react when the network mobility is increased during thermal postcuring treatments. Therefore, the light intensity at which the resin is cured strongly affects the network structure, consequently affecting the ultimate mechanical properties. This work provides a complete characterization of UV-cured methacrylate systems. It reveals that no direct correlation exists between reaction kinetics and mechanical properties because of the dependence of the microstructure on the processing conditions. Hence, microstructural information is required to relate mechanical properties to processing conditions. However, experimentally determining the relevant microstructural characteristics is not trivial.

\section{ASSOCIATED CONTENT}

\section{Supporting Information}

The Supporting Information is available free of charge at https://pubs.acs.org/doi/10.1021/acs.macromol.9b01439. .

Sensitivity study for the model (PDF)

\section{AUTHOR INFORMATION}

\section{Corresponding Author}

*E-mail: L.C.A.v.Breemen@tue.nl. Phone: +31(0)40 247 3092.

\section{ORCID}

R. Cardinaels: 0000-0002-4191-6504

L. C. A. van Breemen: 0000-0002-0610-1908

\section{Author Contributions}

${ }^{\S}$ R.A. and W.P. contributed equally to this work.

\section{Notes}

The authors declare no competing financial interest.

\section{ACKNOWLEDGMENTS}

This work forms part of the research programme of the Brightlands Materials Center (BMC). The authors thank the groups of Macromolecular and Organic Chemistry for the use of the FTIR equipment.

\section{REFERENCES}

(1) Bártolo, P. J. Stereolithography; Springer, 2011.

(2) Lecamp, L.; Youssef, B.; Bunel, C.; Lebaudy, P. Photoinitiated polymerization of a dimethacrylate oligomer: 1. Influence of photoinitiator concentration, temperature and light intensity. Polymer 1997, 38, 6089-6096.

(3) Fuh, J. Y. H.; Lu, L.; Tan, C. C.; Shen, Z. X.; Chew, S. Processing and characterising photo-sensitive polymer in the rapid prototyping process. J. Mater. Process. Technol. 1999, 89-90, 211-217. 
(4) Fuh, J. Y. H.; Chew, S. Curing characteristics of acrylic photopolymer used in stereolithography process. Rapid Prototyp. J. 1999, 5, 27-34.

(5) Ang, B. Y.; Chua, C. K.; Du, Z. H. Study of trapped material in rapid prototyping parts. Int. J. Adv. Manuf. Technol. 2000, 16, 120130.

(6) Onuh, S. O.; Hon, K. K. B. Improving stereolithography part accuracy for industrial applications. Int. J. Adv. Manuf. Technol. 2001, 17, 61-68.

(7) Lu, L.; Fuh, J. Y. H.; Nee, A. Y. C.; Kang, E. T.; Miyazawa, T.; Cheah, C. M. Origin of shrinkage, distortion and fracture of photopolymerized material. Mater. Res. Bull. 1995, 30, 1561-1569.

(8) Achilias, D. S.; Kipasissides, C. Development of a General Mathematical Framework for Modeling Diffusion-Controlled FreeRadical Polymerization Reactions. Macromolecules 1992, 25, 37393750.

(9) Andrzejewska, E. Photopolymerization kinetics of multifunctional monomers. Prog. Polym. Sci. 2001, 26, 605-665.

(10) Bowman, C. N.; Kloxin, C. J. Toward an enhanced understanding and implementation of photopolymerization reactions. AIChE J. 2008, 54, 2775-2795.

(11) Lovell, L. G.; Newman, S. M.; Donaldson, M. M.; Bowman, C. $\mathrm{N}$. The effect of light intensity on double bond conversion and flexural strength of a model, unfilled dental resin. Dent. Mater. 2003, $19,458-465$.

(12) Nomoto, R.; Uchida, K.; Hirasawa, T. Effect of light intensity on polymerization of light-cured composite resins. Dent. Mater. J. 1994, 13, 198-205.

(13) Miyazaki, M.; Oshida, Y.; Keith Moore, B.; Onose, H. Effect of light exposure on fracture toughness and flexural strength of lightcured composites. Dent. Mater. 1996, 12, 328-332.

(14) Lovell, L. G.; Lu, H.; Elliott, J. E.; Stansbury, J. W.; Bowman, C. $\mathrm{N}$. The effect of cure rate on the mechanical properties of dental resins. Dent. Mater. 2001, 17, 504-511.

(15) Goodner, M. D.; Bowman, C. N. Development of a comprehensive free radical photopolymerization model incorporating heat and mass transfer effects in thick films. Chem. Eng. Sci. 2002, 57, $887-900$.

(16) Keramopoulos, A.; Kiparissides, C. Development of a comprehensive model for diffusion-controlled free-radical copolymerization reactions. Macromolecules 2002, 35, 4155-4166.

(17) Gleeson, M. R.; Liu, S.; Guo, J.; Sheridan, J. T. Non-local photo-polymerization kinetics including multiple termination mechanisms and dark reactions: Part III Primary radical generation and inhibition. J. Opt. Soc. Am. B 2010, 27, 1804.

(18) Boddapati, A. Modeling Cure Depth During Photopolymerization of Multifunctional Acrylates. M.Sc. Thesis, Georgia Institute of Technology, May, 2010.

(19) Jariwala, A. S.; Ding, F.; Boddapati, A.; Breedveld, V.; Grover, M. A.; Henderson, C. L.; Rosen, D. W. Modeling effects of oxygen inhibition in mask-based stereolithography. Rapid Prototyp. J. 2011, 17, $168-175$.

(20) Young, R. J.; Lovell, P. A. Introduction to Polymers; Chapman and Hall, 2011; Vol. 3.

(21) Decker, C. Kinetic Analysis and Performance of UV-Curable Coatings. Radiation Curing; Springer, 1992; pp 135-179.

(22) Chatani, S.; Kloxin, C. J.; Bowman, C. N. The power of light in polymer science: photochemical processes to manipulate polymer formation, structure, and properties. Polym. Chem. 2014, 5, 21872201.

(23) Anseth, K. S.; Bowman, C. N. Reaction diffusion enhanced termination in polymerizations of multifunctional monomers. Polym. React. Eng. 1993, 1, 499-520.

(24) Anseth, K. S.; Wang, C. M.; Bowman, C. N. Kinetic Evidence of Reaction Diffusion during the Polymerization of Multi(meth)acrylate Monomers. Macromolecules 1994, 27, 650-655.

(25) Arlman, E. J.; Wagner, W. M. Volume contraction and conversion in the bulk polymerization of vinylidene chloride and vinyl chloride. Trans. Faraday Soc. 1953, 49, 832.
(26) Achilias, D. S. A review of modeling of diffusion controlled polymerization reactions. Macromol. Theory Simul. 2007, 16, 319347.

(27) Hale, A.; Macosko, C. W.; Bair, H. E. Glass transition temperature as a function of conversion in thermosetting polymers. Macromolecules 1991, 24, 2610-2621.

(28) Pascault, J. P.; Williams, R. J. J. Glass transition temperature versus conversion relationships for thermosetting polymers. J. Polym. Sci., Part B: Polym. Phys. 1990, 28, 85-95.

(29) Nielsen, L. E. Cross-Linking-Effect on Physical Properties of Polymers. J. Macromol. Sci., Part C: Polym. Rev. 1969, 3, 69-103.

(30) DiBenedetto, A. T. Prediction of the glass transition temperature of polymers: A model based on the principle of corresponding states. J. Polym. Sci., Part B: Polym. Phys. 1987, 25, 1949-1969.

(31) Adabbo, H. E.; Williams, R. J. J. The evolution of thermosetting polymers in a conversion-temperature phase diagram. J. Appl. Polym. Sci. 1982, 27, 1327-1334.

(32) Couchman, P. R. Thermodynamics and the Compositional Variation of Glass Transition Temperatures. Macromolecules 1987, 20, $1712-1717$.

(33) Eyring, H. Viscosity, plasticity, and diffusion as examples of absolute reaction rates. J. Chem. Phys. 1936, 4, 283-291.

(34) Anastasio, R.; Maassen, E. E. L.; Cardinaels, R.; Peters, G. W. M.; van Breemen, L. C. A. Thin film mechanical characterization of uv-curing acrylate systems. Polymer 2018, 150, 84-94.

(35) Whitbeck, M. R. Second Derivative Infrared Spectroscopy. Appl. Spectrosc. 1981, 35, 93-95.

(36) Collares, F. M.; Portella, F. F.; Leitune, V. C. B.; Samuel, S. M. W. Discrepancies in degree of conversion measurements by FTIR. Braz. Oral Res. 2014, 28, 9-15.

(37) Stansbury, J. W. Dimethacrylate network formation and polymer property evolution as determined by the selection of monomers and curing conditions. Dent. Mater. 2012, 28, 13-22.

(38) Gupta, V. B.; Brahatheeswaran, C. Molecular packing and free volume in crosslinked epoxy networks. Polymer 1991, 32, 1875-1884.

(39) Lovelh, L. G.; Newman, S. M.; Bowman, C. N. The effects of light intensity, temperature, and comonomer composition on the polymerization behavior of dimethacrylate dental resins. J. Dent. Res. 1999, 78, 1469-1476.

(40) Decker, C. The use of UV irradiation in polymerization. Polym. Int. 1998, 45, 133-141.

(41) Tripathy, R.; Crivello, J. V.; Faust, R. Photoinitiated polymerization of acrylate, methacrylate, and vinyl ether endfunctional polyisobutylene macromonomers. J. Polym. Sci., Part A: Polym. Chem. 2013, 51, 305-317.

(42) Suzuki, Y.; Cousins, D.; Wassgren, J.; Kappes, B. B.; Dorgan, J.; Stebner, A. P. Kinetics and temperature evolution during the bulk polymerization of methyl methacrylate for vacuum-assisted resin transfer molding. Composites, Part A 2018, 104, 60-67.

(43) Unterbrink, G. L.; Muessner, R. Influence of light intensity on two restorative systems. J. Dent. 1995, 23, 183-189.

(44) Li, C.; Strachan, A. Evolution of network topology of bifunctional epoxy thermosets during cure and its relationship to thermo-mechanical properties: A molecular dynamics study. Polymer 2015, 75, 151-160.

(45) Steyrer, B.; Neubauer, P.; Liska, R.; Stampfl, J. Visible light photoinitiator for $3 \mathrm{D}$-printing of tough methacrylate resins. Materials 2017, 10, 1445.

(46) Caelers, H. J. M.; Parodi, E.; Cavallo, D.; Peters, G. W. M.; Govaert, L. E. Deformation and failure kinetics of ipp polymorphs. J. Polym. Sci., Part B: Polym. Phys. 2017, 55, 729-747.

(47) Parodi, E.; Peters, G. W. M.; Govaert, L. E. Prediction of plasticity-controlled failure in polyamide 6: influence of temperature and relative humidity. J. Appl. Polym. Sci. 2018, 135, 45942.

(48) Cook, W. D.; Mayr, A. E.; Edward, G. H. Yielding behaviour in model epoxy thermosets-II. Temperature dependence. Polymer 1998, 39, 3725-3733. 
(49) Tcharkhtchi, A.; Faivre, S.; Roy, L. E.; Trotignon, J. P.; Verdu, J. Mechanical properties of thermosets. J. Mater. Sci. 1996, 31, 26872692. 